\title{
Advances in Glycation: from food to human health and disease
}

\author{
Naoyuki Taniguchi ${ }^{1}$ (D) $\cdot$ Masatsune Murata $^{2}$
}

Received: 11 February 2021 / Revised: 11 February 2021 / Accepted: 15 February 2021 / Published online: 19 March 2021

(C) The Author(s) 2021

\begin{abstract}
This Special Issue on "Advances in Glycation: from food to human health and disease" was planned after the XXV International Symposium on Glycoconjugates (Glyco25) in Milan in order to ask special attention of importance of glycation to glycoscience community. In addition, we also celebrate the 30th anniversary of JMARS (Japan Maillard Reaction Society), and dedicated to one of the pioneers of this field, Professor Vincent Monnier, MD. He contributed enormously to studies on glycation related to aging and diseases to date and also he contributed to establish IMARS (International Maillard Reaction Society) as well as JMARS.
\end{abstract}

Keywords Maillard reaction - Glycation of food - Glycation in disease - Advanced Glycation Endproducts (AGEs) . Pigmentation · Browning · International Maillard Reaction Society (IMARS) · Japan Maillard Reaction Society (JMARS)

This special issue entitled "Advances in Glycation: from Food to Human Health and Diseases "was planned to appear after the XXV International Symposium on Glycoconjugates (Glyco25) in Milan in 2019, which was organized by Sandro Sonnino (University of Milan, chief editor of the Glycoconjugate J.) [1]. After the meeting was over, we proposed to publish a special issue focusing on glycation studies mainly taken from the speakers who attended this meeting.

When the 12th International Maillard Reaction Society (IMARS) was held in Tokyo in 2015, organized by the Japan Maillard Reaction Society (JMARS), a special issue entitled "Advanced glycation in diabetes, aging and agerelated diseases: editorial and dedication "as published in the Glycoconjugate. J by Vincent Monnier and Naoyuki Taniguchi [2].

Sonnino also agreed with our proposal, and he also emphasized the importance of glycation research in Glycoconjugate

Naoyuki Taniguchi

glycotani@mc.pref.osaka.jp

Masatsune Murata

murata.masatsune@ocha.ac.jp

1 Department of Glyco-Oncology and Medical Biochemistry, Osaka International Cancer Institute, 3-1-69 Otemae, Chuo-ku, 541-8567 Osaka, Japan

2 Department of Nutrition and Food Science, Ochanomizu University, 2-1-1 Otsuka, Bunkyo-ku, Tokyo 112-8610, Japan research. Based on a survey of PubMed, the number of published papers related to glycation and Advanced Glycation Endproducts (AGEs) has increased dramatically in the past ten-odd years, as shown in the Fig. 1.

It is now well known that the Maillard reaction was first reported by Louis Camile Maillard at the Sorbonne University in 1912 [3]. In this report, he reported on the reaction products that are produced when aqueous solutions of reducing sugars turn progressively yellow-brown when heated or when stored under physiological conditions. Even though glycation, i.e., the Maillard reaction or the browning reaction or the aminocarbonyl reaction are quite common words in the field of food science and agricultural biochemistry, most people who are studying enzymatic glycosylation are not so familiar with this terminology. Moreover, the community of scientists who are involved in research regarding the Maillard reaction is rather small and drawing the attention of other members of the glycoconjugate community to this subject is important.

In medical science, since hemoglobin A1c was found to be a biomarker for serum glucose levels in diabetes mellitus [4] and moreover, excellent research on the Amadori rearrangement by John E. Hodge [5] and on advanced glycation end products (AGE) in aging and diabetes by Monnier and Anthony Cerami [6], Michael Brownlee [7], and John Baynes and Suzanne Thorpe [8], Antoinette Pirie [9]. Helen Vlassara [10] and many others also have caused this to attract the interest of members of the biomedical research community. 


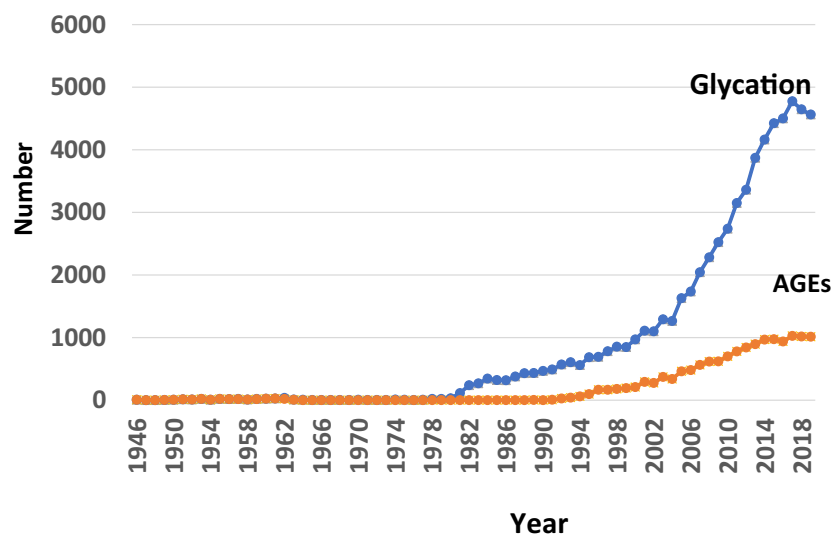

Fig. 1 Increase of published papers on glycation and Advanced Glycation Endproducts (AGEs) calculated from PubMed

In addition, in Japan we had a long history of research on the browning reaction in food science because various Japanese fermented food items such as Miso, Shoyu and $\mathrm{Su}$ (rice vinegar) undergo browning reactions under maturation. The pioneering studies on the Maillard reaction in food science include research by Masao Fujimaki (University of Tokyo), Michio Namiki (Nagoya University) and Masamichi Kato (University of Tokyo) [11] and their colleagues. Several scientists from Japan spent time working with Monnier (Fumitaka Hayase, Satoshi Miyata, Motoko Takahashi, Shinji Taneda, Yoko Nishikawa, Masao Satake), Cerami (Zenji Makita and Masanobu Kawakami) and Baynes (Ryoji Nagai) as postdocs, and after they came back to Japan, they have continued their studies in academia or private clinics on the importance of glycation in medical science.

In 1989 Taniguchi (at that time at the Osaka University Medical School) discussed the Maillard reaction with Kato and Hidetaka Nakayama (a diabetologist at Hokkaido University) and launched the first research meeting on glycated proteins. This meeting has been held every year since then, even though the meeting name has been changed to JMARS. Therefore, in 2019 we hosted the 30th memorial meeting and, because of this, we felt that this would be a good occasion to publish a special issue.

Several distinguished scientists had been invited make presentations in the glycation session at the Glyco25 meeting and they gave excellent presentations. Among the International Maillard Society (IMARS) members, Vincent Monnier, a pioneer in this field, Paul Thornalley (Harmad Bin Khalifa University,), the president of IMARS、 and Naira Rabbani (University of Warwick) were attendees, and from JMARS, the secretary general of JMAS, Yasuhiko Yamamoto (Kanazawa University) and Rhoji Nagai (Kumamoto University) were present along with several internationally known scientists who worldwide participated in this session (Fig. 2).

In this issue Murata reports an update on browning and pigmentation in food through the Maillard reaction and other authors mainly focused on glycation in the medical sciences.

Main speakers and organizers at the session of glycation at Glyco25.
Fig. 2 A group photo of main speakers and organizers taken at the session of glycation in Glyco25

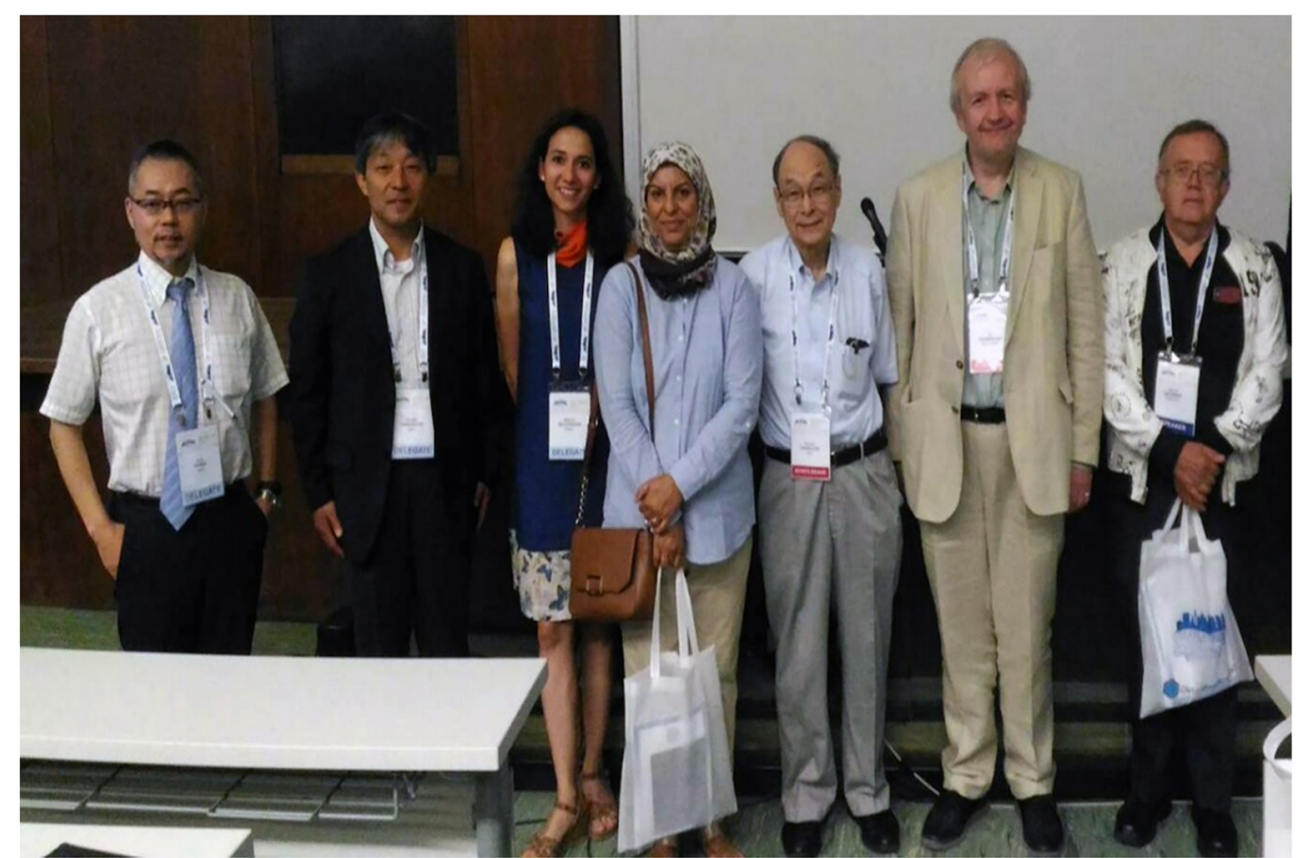


Acknowledgements We wish to thank Dr. Sandro Sonnio for giving us the opportunity to publish this special issue. We apologize to abbreviated titles such as the use of the term Dr. and for not citing all relevant scientists due to space limitations. We wish to acknowledge Dr. Milton Feather, one of the 2nd IMARS organizers for his English editing. and Ms. Miyuki Kusakawa for calculating the number of publications from PubMed. NT acknowledges travel support from JSPS, Japan (Japan Society for the Promotion of Science (JP18K06914).

\section{Declarations}

Ethical approval This article does not contain any studies with human participants or animals performed by any of the authors.

Conflict of interest The authors declare that they have no conflicts of interest.

Open Access This article is licensed under a Creative Commons Attribution 4.0 International License, which permits use, sharing, adaptation, distribution and reproduction in any medium or format, as long as you give appropriate credit to the original author(s) and the source, provide a link to the Creative Commons licence, and indicate if changes were made. The images or other third party material in this article are included in the article's Creative Commons licence, unless indicated otherwise in a credit line to the material. If material is not included in the article's Creative Commons licence and your intended use is not permitted by statutory regulation or exceeds the permitted use, you will need to obtain permission directly from the copyright holder. To view a copy of this licence, visit http://creativecommons.org/licenses/by/4.0/.

\section{References}

1. Glyco25.: XXV International Symposium on Glycoconjugates. Glycoconj. J. 36, 267-397 (2019)
2. Monnier, V.M., Taniguchi, N.: Advanced glycation in diabetes, aging and age-related diseases: conclusions. Glycoconj. J. 33, 691-692 (2016)

3. Maillard, L.-C.: Action of amino acids on sugars. Formation of melanoidins in a methodical way (in French). Compt. Rend. 154, 66-68 (1912)

4. Trivelli, L.A., Ranney, H.M., Lai, H.T.: Hemoglobin components in patients with diabetes mellitus. N. Engl. J. Med. 284, 353-357 (1971)

5. Hodge, J.E.: The Amadori rearrangement. Adv. Carbohydr. Chem. 10, 169-205 (1955)

6. Monnier, V.M., Cerami, A.: Nonenzymatic browning in vivo: possible process for aging of long-lived proteins. Science. 211, 491493 (1981)

7. Brownlee, M., Vlassara, H., Kooney, A., Ulrich, P., Cerami, A.: Aminoguanidine prevents diabetes-induced arterial wall protein cross-linking. Science. 232, 1629-1632 (1986)

8. Ahmed, M.U., Thorpe, S.R., Baynes, J.W.: Identification of N epsilon-carboxymethyllysine as a degradation product of fructoselysine in glycated protein. J. Biol. Chem. 261, 4889-4894 (1986)

9. Pirie, A.: Reaction of tyrosine oxidation products with proteins of the lens. Biochem. J. 109, 301-305 (1968)

10. Vlassara, H., Brownlee, M., Manogue, K.R., Dinarello, C.A., Pasagian, A.: Cachectin/TNF and IL-1 induced by glucosemodified proteins: role in normal tissue remodeling. Science. 240, 1546-1548 (1988)

11. Fujimaki, M., Namiki, M., Kato, H. (eds.) Proceeding of the 3rd International Symposium on the Maillard Reaction. the Fuji Institute, Susono, Shizuoka, Japan. Kodansha Ltd. and Elsevier (1986)

Publisher's note Springer Nature remains neutral with regard to jurisdictional claims in published maps and institutional affiliations. 